\section{A CONJUGALIDADE DIANTE DO ENFRENTAMENTO DE MÚLTIPLOS ESTRESSORES: UM ESTUDO DE CASO SOBRE UMA TERAPIA DE CASAL INVOLUNTÁRIA}

\author{
MARITAL RELATIONS IN THE FACE OF MULTIPLE STRESSORS:
} A CASE STUDY ON AN INVOLUNTARY COUPLE THERAPY

\section{RELACIONES MATRIMONIALES FRENTE A MÚLTIPLES FACTORES ESTRESANTES: UN ESTUDIO DE CASO SOBRE UNA TERAPIA DE PAREJA INVOLUNTÁRIA}

RESUMO: Neste artigo, investigamos a experiência da conjugalidade em um contexto de múltiplos estressores. Realizamos um estudo de caso do qual participou um casal que iniciou o processo terapêutico por recomendação da instituição em que seus filhos se encontravam acolhidos. Os dados foram submetidos a uma análise narrativa e discutidos a partir da abordagem sistêmica, com o intuito de compreender a dinâmica relacional do casal e refletir sobre estratégias e intervenções a serem utilizadas nesse contexto. Destacamos as dificuldades enfrentadas pela sobreposição de múltiplos estressores, como uso abusivo de álcool e drogas, violência doméstica e acolhimento dos filhos. Ressaltamos a necessidade de uma abordagem terapêutica contextualizada.

Palavras-chave: relacionamento conjugal; acolhimento institucional; violência doméstica; estressores.

ABSTRACT: This article investigated the experience of conjugality in the context of multiple stressors. A case study was conducted in which a couple who started the therapeutic process participated in the recommendation of the institution in which their children were welcomed. The data were submitted to a narrative analysis and discussed from the systemic approach, to understand the relational dynamics of the couple and reflect on strategies and interventions to be used in this context. The difficulties faced by overlapping multiple stressors, such as alcohol and drug abuse, domestic violence, and childcare, stood out. The need for a contextualized therapeutic approach is highlighted.

Keywords: marital relations; institutional shelter; domestic violence; stressors.

RESUMEN: Este artículo investigó la experiencia de la conjugalidad en un contexto de múltiples factores estresantes. Se llevó a cabo un estudio de caso en el que una pareja que inició el proceso terapéutico participó por recomendación de la institución en la que sus hijos fueron acogidos. Los datos fueron sometidos a un análisis narrativo y discutidos desde el enfoque sistémico, con el fin de entender la dinámica relacional de la pareja y reflexionar sobre las estrategias e intervenciones que se utilizarán en este contexto. Destacaron las dificultades a las que se enfrentan la superposición de múltiples factores estresantes, como el abuso de alcohol y drogas, la violencia doméstica y el cuidado de niños. Se pone de relieve la necesidad de un enfoque terapéutico contextualizado.

Palabras clave: relación conyugal; amparo institucional; violencia doméstica; estresores.
ANA DÓRIS DA SILVA ${ }^{1}$

ISABELA MACHADO DA SILVA ${ }^{2}$

${ }^{1}$ Faculdade de Psicologia e Ciências da Educação da Universidade do Porto, Porto, Portugal

${ }^{2}$ Universidade de Brasília (UnB), Brasilia/DF, Brasil

Recebido em: 04/11/2019 Aprovado em: 15/05/2020 
Por se tratar do primeiro grupo social no qual o homem está inserido, a família é considerada o microssistema mais importante para o desenvolvimento dos indivíduos. Suas funções primordiais residem na sobrevivência e na socialização primária de crianças e adolescentes, tratando-se de um espaço indispensável para a sobrevivência, a proteção e o provimento das necessidades básicas e emocionais de seus membros (Sousa et al., 2014).

Existem famílias que, ao longo da sua trajetória desenvolvimental, se defrontam com múltiplos fatores que são considerados estressantes e que as caracterizam como um sistema vulnerável e de alto risco, em que não se observa apenas um sintoma em particular, mas uma série de dificuldades, dentre as quais podemos mencionar: violência conjugal e familiar, institucionalização dos filhos e uso de álcool e/ou outras drogas (Calvo, 2004; Cancrini, de Gregorio, \& Nocerino, 2010; Gómez, Muñoz, \& Haz, 2007; Martinez, 2003). Essas famílias foram abordadas pela literatura a partir de diferentes nomenclaturas, destacando-se a de famílias multiproblemáticas (Prati, Couto, \& Koller, 2009).

O conceito de famílias multiproblemáticas surgiu nos anos 1950, na Inglaterra, na área de serviço social, para se referir às famílias de baixo poder econômico. Posteriormente foram incorporadas ao conceito características relativas às relações estabelecidas entre os membros do grupo familiar e às relações que essas famílias estabelecem com os profissionais e com os serviços de atenção e cuidado, visto que tendem a apresentar alto nível de dependência desses serviços e dos profissionais que as atendem. Não obstante Sousa e Ribeiro (2005) apontem que, em muitos dos casos, os conceitos de multiproblematicidade e pobreza sejam utilizados, na prática, como sinônimos, estes e outros autores (Martinez, 2003) alertam para o fato de que "ser pobre não significa necessariamente ser disfuncional” (Sousa \& Ribeiro, 2005 p. 6). Se considerarmos o baixo nível de organização, o não cumprimento das próprias regras familiares, em especial no que diz respeito ao subsistema parental, além das dificuldades nas relações interpessoais e na comunicação entre os membros, existem famílias de diferentes níveis socioeconômico e cultural que podem apresentar características que as situem como famílias multiproblemáticas (Calvo, 2004).

Com o passar do tempo, no entanto, "surgiram defensores de uma abordagem baseada nos aspectos positivos do sistema que substituíram a expressão famílias multiproblemáticas por famílias em alto risco ou multinecessitadas" (Prati et al., 2009, p. 405). Nessa mesma direção, Madsen (2010) propôs o termo famílias multiestressadas, que será utilizado neste trabalho. De acordo com esse autor, que fundamenta seu trabalho em uma abordagem construcionista social, essas distinções são importantes, pois a forma como conceituamos a família influencia a maneira como trabalharemos com ela. Assim, o termo multiestressadas destacaria não os déficits presentes nessas famílias, mas as pressões às quais são submetidas, o que envolve limitações contextuais e fatores socioculturais.

A maioria dos programas sociais tem trabalhado com famílias multiestressadas em situação de pobreza e risco social. Entretanto, várias são as razões que dificultam a obtenção de resultados positivos com essas famílias (Gómez et al., 2007): (a) basear-se nas deficiências, (b) concentrar-se nos indivíduos, (c) reagirem apenas nas crises, (d) atribuir aos profissionais a capacidade de definirem as necessidades dos seus clientes. Por outro lado, é importante registrar que, em decorrência da ação de vários equipamentos de atenção e cuidado sobre uma mesma família, observase uma invasão progressiva em todas as áreas da vida familiar, que desarticula as estruturas familiares sem observar os vínculos emocionais positivos existentes, anulando possíveis recursos de que a família já disponha (Gómez et al., 2007). 
Dessa forma, tornam-se necessários estudos que considerem as potencialidades dessas famílias e as dinâmicas relacionais presentes no sistema.

Este artigo apresenta uma reflexão sobre o atendimento psicoterápico de um casal que se encontrava em contexto familiar de múltiplos estressores. A abordagem sistêmica foi utilizada para compreender a dinâmica relacional do casal e para refletir acerca de possíveis estratégias e intervenções a serem utilizadas nesse contexto.

\section{MÉTODO}

\section{Delineamento}

Esta foi uma pesquisa qualitativa de caráter exploratório. Nela, utilizamos o método de estudo de caso, por permitir desenvolver hipóteses passíveis de serem compreendidas de forma empírica, a partir da experiência vivida pelos participantes, e por oportunizar que suas características possam ser estendidas a outros casos a partir do raciocínio explicativo (Serralta, Nunes, \& Elzirik, 2011). Estudos de caso mostram-se úteis quando o pesquisador tem pouco controle sobre os acontecimentos e o foco do trabalho está em fenômenos inseridos em contextos da vida real (Yin, 2001).

\section{Participantes e Procedimentos}

O presente estudo se desenvolveu a partir do atendimento psicoterápico prestado pela primeira autora deste trabalho ao casal Fernando (34) e Isabel (29). O casal possuía três filhos menores, com idades entre 2 e 6 anos. Os atendimentos foram realizados com periodicidade quinzenal no espaço terapêutico próprio da terapeuta. $\mathrm{O}$ casal foi atendido em nove sessões conjuntas, que tinham duração de aproximadamente duas horas cada. Quando o processo terapêutico teve início, os filhos do casal estavam abrigados em instituição especializada há cerca de um ano.

Para a realização do trabalho de pesquisa, foram utilizados os registros pessoais da terapeuta, que se referiram a todas as sessões realizadas no período de atendimento. Os registros das sessões foram realizados imediatamente após o encerramento de cada um dos atendimentos.

\section{Considerações Éticas}

Visando dar transparência ao procedimento de coleta de dados, o casal foi esclarecido quanto aos objetivos da pesquisa, assinando o Termo de Consentimento Livre e Esclarecido (TCLE). O estudo não foi submetido ao comitê de ética em pesquisa, considerando o disposto no Art. $1^{\circ}$, item VII, $\$$ único da Resolução no 510 de 05 de abril de 2016 (Conselho Nacional de Saúde, 2016). Os participantes são aqui apresentados com nomes fictícios, visando à preservação de suas identidades, e foram omitidas informações que pudessem permitir sua identificação. 


\section{Análise dos Dados}

Utilizamos o modelo de análise narrativa proposto por Polkinghorne (1995), que consiste na organização dos dados de forma cronológica e coerente. Constituída por eventos e ações e por meio da configuração dos dados, "a análise narrativa consiste na explanação retrospectiva de um conjunto de informações que permitem a formação de um enredo" (p.16).

\section{RELATO DO CASO}

\section{História do Casal}

No que se refere às suas famílias de origem, Isabel é filha de pais já falecidos. Os pais de Fernando separaram-se quando ele ainda era criança e sua mãe casou-se novamente. Fernando passou então a morar com diferentes parentes.

Cada um dos cônjuges tinha um filho de relacionamentos anteriores. O filho de Fernando residia com a avó materna e o filho de Isabel residia com o pai. Fernando tinha pouco contato com esse filho devido a dificuldades de relacionamento com a ex-esposa, enquanto Isabel se encontrava com seu filho semanalmente. Isabel relatou que sempre quis ter uma família e casou-se com esse objetivo. Disse acreditar que esse desejo é decorrente de sua carência afetiva, uma vez que seus pais não formaram a família que ela idealizou.

Fernando e Isabel estavam casados há 5 anos quando iniciaram a terapia de casal. Aproximadamente um ano antes, a mãe de Fernando realizou uma denúncia ao Conselho Tutelar que culminou no acolhimento institucional dos filhos do casal e no rompimento entre Fernando e sua mãe.

De acordo com o descrito no documento Solicitação de Atendimento emitido pela instituição de acolhimento, "a genitora apresentava descontroles emocionais", além de a família ter vivenciado episódios de violência intrafamiliar, sendo o caso "acompanhado pela Promotoria de Violências Domésticas devido às inúmeras discussões do casal". Fernando e Isabel confirmaram a ocorrência de brigas constantes, sendo que Isabel registrou essas ocorrências amparada pela Lei Maria da Penha.

Fernando e Isabel admitiram perder o controle em determinadas situações. Por exemplo, depois de uma briga do casal na qual foi agredida pelo marido, Isabel ateou fogo à casa onde moravam, mesmo sabendo que, em seu interior, estava dormindo um dos filhos do casal. Para Fernando, as brigas aconteciam porque existiam divergências na forma como cada um encarava os acontecimentos da vida a dois, enquanto Isabel acreditava que as brigas aconteciam porque Fernando tinha comportamentos com os quais ela não concordava, como, por exemplo, o uso de álcool e outras drogas, além do fato de Fernando não corresponder às suas expectativas como marido e pai.

\section{A Busca pelo Atendimento Psicoterápico}

O casal estava sendo acompanhado pela Promotoria de Justiça Especial Criminal e de Defesa da Mulher em Situação de Violência Doméstica devido aos episódios de violência doméstica. Isabel relatou que, em atendimento à recomendação da Promotoria, já se encontrava em atendimento psicoterápico individual. A terapia de casal, por sua vez, foi buscada também diante da recomendação de uma das instituições 
que acompanhava o casal. Entretanto, o casal, em nenhum dos encontros realizados, mencionou esse encaminhamento, destacando apenas suas motivações pessoais.

Para Fernando, "a vinda para a terapia foi porque ele não conseguia acertar... e essa dificuldade que teria para agir com acerto, provocou muitas confusões em nossa vida...." Para Isabel, "a vinda para a terapia foi uma oportunidade para melhorar o relacionamento para quando as crianças voltarem pra casa...".

\section{Evolução dos Atendimentos}

Isabel relacionava seu comportamento agressivo e/ou violento ao objetivo de chamar atenção de Fernando para si mesma. Ressaltava que Fernando fazia uso de álcool e outras drogas desde antes do casamento, enfatizando que esse comportamento do marido estava se intensificado ao longo do tempo.

Isabel lamentava a perda recente de sua mãe. Embora reconhecesse que teve pouco contato com ela durante sua infância, em virtude do trabalho materno, colocava que sua mãe sempre esteve próxima quando ela precisava. Apesar de ambos serem profissionais autônomos e de possuírem espaço próprio para o desempenho dessa atividade, enfatizava seu desejo de que Fernando se estabelecesse em um emprego que permitisse garantir a subsistência da família, visto que, até aquele momento, a renda vinha sendo obtida por intermédio de vínculos com programas sociais oferecidos pelo Governo Federal e de provimentos obtidos em decorrência da realização de trabalhos esporádicos. Registrava, ainda, a esperança de que os filhos retornassem ao lar em breve, visto que já se encontravam afastados havia muito tempo. Além disso, apresentava a expectativa de que, com o processo terapêutico, Fernando pudesse reconhecer sua preocupação com o bem-estar dele.

Por acreditar que Isabel tinha mais facilidade para expressar os pensamentos, Fernando abriu mão de contar a história do casal para que ela o fizesse. Assim, optou por registrar apenas os seus sentimentos e entendimentos com relação ao momento que estavam vivenciando. Reconhecia que tinha alguns comportamentos que podiam eventualmente contribuir para a falta de harmonia na relação do casal, como, por exemplo, falta de paciência, não conversar, não entender algumas necessidades dela. Entretanto, observava que algumas de suas dificuldades só se apresentavam na relação porque não tinha o mesmo nível de valoração dos acontecimentos que Isabel, isto é, "coisas que, para mim, não são importantes, para ela são muito valorizadas", como, por exemplo, colocar sapatos, roupas e panelas fora do lugar. Ele admitia que, devido ao uso de álcool e outras drogas, tinha grande parcela de responsabilidade no processo que fez a história do casal chegar até aquele ponto, visto que o uso de drogas provocava ausências prolongadas e faltas aos compromissos com clientes, ao que ela acrescentou: "você não acha que falta humildade também?".

Isabel enfatizava sua preocupação com as dificuldades financeiras que estavam vivenciando, uma vez que estavam aguardando o retorno das crianças para o convívio familiar. Ela temia pela subsistência da família, em especial no que se refere à alimentação, tendo em vista que os compromissos financeiros estavam se acumulando devido ao fato de que Fernando não estava colaborando com as despesas do grupo familiar.

Fernando relatava que, por recomendação da técnica da instituição de acolhimento em que estavam as crianças, conseguiu emprego em uma instituição social e estava trabalhando como educador na área esportiva, ressaltando seu bem-estar por realizar essa atividade. Isabel mencionava que, depois de iniciado o processo terapêutico, estava tentando modificar sua forma de se relacionar com Fernando. 
Entretanto, referia ainda sentir dificuldades para lidar com seus sentimentos quando tentava ligar para Fernando e ele não atendia. Quando Fernando se ausentava de casa por mais de 24 horas, seja devido ao uso de álcool e outras drogas, seja por outra razão, e Isabel não conseguia falar com ele pelo celular, ela reagia de forma intensa e chegava a exibir comportamentos como o de quebrar o celular dele.

A pontualidade do casal para os encontros terapêuticos durante todo o processo foi irregular. O casal apontava a preocupação com possíveis sanções dos empregadores de Fernando como sendo o motivo que dificultava o cumprimento do horário. Fernando não informara seus empregadores acerca da necessidade de frequentar a terapia, que ambos encaravam como um dos recursos disponíveis para auxiliar a decisão do juiz no que tangia ao restabelecimento da guarda dos filhos.

Durante o período de realização dos encontros terapêuticos, o casal conseguiu autorização para ter as crianças em sua residência durante os finais de semana, sendo que ambos demonstraram muita satisfação com isso. Não obstante, a presença das crianças destacou a necessidade de a habitação oferecer condições adequadas para a sua permanência e para que fossem assegurados os meios necessários para sua subsistência.

Esses aspectos se caracterizavam como um dos fatores estressantes na relação do casal, visto que Isabel acreditava que a promoção de condições adequadas de alimentação e habitação era uma atribuição inerente ao papel de pai e provedor de uma família. Assim, de acordo com sua visão dos fatos, Fernando não estava desempenhando adequadamente esse papel, pois, apesar de estar trabalhando, seus recursos financeiros não apareciam na composição do orçamento familiar.

Durante os atendimentos realizados e tendo em vista o teor das falas dos cônjuges, observamos dificuldades na comunicação do casal. Isabel apresentava afirmações como "eu não aguento a falta de inteligência dele, que não percebe que a casa está precisando de reparos e não faz nada...”; “...ele não cumpre com o papel dele... o comportamento do Fernando não é comportamento de homem..."; "a despensa está vazia... eu quero ir ao supermercado... a gente tá vivendo da cesta básica que o serviço social dá, e ele não faz nada...". Fernando, por sua vez, argumentava: "nada do que você fale vai adiantar...". Além disso, Isabel mantinha o comportamento de destruir os objetos que eram utilizados pelo casal, fossem objetos de uso pessoal, como roupas ou o aparelho celular, ou ainda objetos de uso familiar, como móveis, eletrodomésticos ou outros utensílios de uso doméstico.

Isabel relatava que Fernando constantemente ingeria bebidas alcoólicas. Fernando, por sua vez, dizia saber da necessidade de interromper o uso de bebidas alcoólicas e de maconha, visto que entendia que esse consumo dificultava sua relação com Isabel, seu comprometimento com o trabalho e o provimento das necessidades do casal e da família. No entanto, mantinha o comportamento de ausentar-se de casa por período prolongado para fins de consumo de álcool e/ou outras drogas. Cada vez que Fernando se ausentava do lar por um período prolongado, tanto Fernando como Isabel manifestavam comportamentos violentos.

Por outro lado, foi possível observar, durante as sessões, manifestações de afeto quando se dirigiam um ao outro, como, por exemplo, nesta fala de Isabel: “As crianças passaram o final de semana conosco, e foi muito bom... não é, amor?". O casal também não mencionou dificuldades no que tange ao relacionamento sexual.

Durante o processo terapêutico, foram realizadas intervenções com o objetivo de oportunizar ao casal observar, identificar e refletir acerca de suas posições e atuações no contexto familiar. Esperava-se, assim, contribuir para a realização de possíveis mudanças nos padrões interacionais que viessem a melhorar a qualidade da relação conjugal.

Nova Perspectiva Sistêmica, v. 29, n. 67, p. 41-55, agosto 2020. 
Ao longo do processo terapêutico, Isabel reconheceu que existiam algumas iniciativas que ela poderia adotar para criar um contexto mais harmonioso na relação do casal, tais como: (a) a importância de "ouvir" antes de "falar", (b) o tom de voz ao falar, que pode indicar um movimento apaziguador ou de violência, (c) esperar o momento certo para registrar suas impressões para ter resultados mais proveitosos. Por outro lado, é importante registrar que Fernando, embora trouxesse em seu discurso que compreendia a necessidade de interromper o uso de álcool e outras drogas, não havia conseguido implementar mudanças nesse sentido.

Depois de vivenciar novo episódio de violência, no qual Isabel sofreu um desmaio, Fernando foi preso e, considerando a existência de queixas anteriores de violência, foi proibido de se aproximar de Isabel (medida protetiva judicial). Nesse contexto, o casal anunciou sua separação e disse acreditar que a separação seria benéfica para a relação familiar. Assim, considerando que as crianças já haviam retornado ao convívio familiar, o casal optou por interromper os encontros terapêuticos, por entender que esses não seriam mais necessários.

\section{DISCUSSÃO}

O caso será discutido de acordo com três dos estressores vivenciados pelo casal no momento da terapia: (a) a institucionalização dos filhos (b) a violência doméstica e (c) o uso de álcool e outras drogas.

\section{A Institucionalização dos Filhos}

A legislação brasileira destaca o direito de crianças e adolescentes à convivência familiar e comunitária, mas prevê que o acolhimento institucional pode ser utilizado como recurso para garantir sua proteção, em situações excepcionais (Estatuto da Criança e do Adolescente, 1990). Segundo o Conselho Nacional do Ministério Público (2003), encontram-se, dentre os motivos que podem levar ao acolhimento institucional, a negligência, a violência e o uso de álcool ou outras drogas. No caso aqui abordado, temos tanto a presença da violência doméstica como o uso de álcool e outras drogas.

Segundo o Conselho Nacional dos Direitos da Criança e do Adolescente (2009), as instituições devem agir de forma a preservar os vínculos entre as crianças, os adolescentes e suas famílias, tendo-se, como meta, a reintegração familiar. Para tanto, Azôr e Vectore (2008) recomendam:

políticas públicas eficazes, quer seja em nível federal, estadual ou municipal, atreladas à intervenção de uma equipe multiprofissional, maximizando e otimizando o atendimento, resgatando a auto-estima das famílias e pautandose na compreensão reflexiva das causas e no reconhecimento dos recursos de natureza externa e interna de que dispõe a família, não se fixando apenas no aspecto financeiro, mas também compreendendo o peso de variáveis afetivas e sociais, na tão almejada reconstrução familiar. (p. 88)

Nesse sentido, identificamos que a instituição de acolhimento dos filhos do casal e as demais instituições que acompanhavam a família propuseram várias medidas com o intuito de favorecer a reintegração familiar: a recomendação de terapia individual e familiar bem como o encaminhamento de Fernando para um novo 
emprego são exemplos disso. A família também contava com o apoio dos serviços de assistência social, que garantiam a renda para sua subsistência.

No entanto, é possível que o acompanhamento de todos esses serviços possa representar um estressor adicional para os membros da família, que podem se sentir constantemente avaliados e em busca de aprovação. Ao falarmos sobre famílias multiestressadas, estamos falando sobre famílias que foram submetidas aos olhares dos mais diversos profissionais, em um contexto em que cada um geralmente apresenta uma recomendação, uma indicação sobre como a família deveria ser, passando-se uma mensagem de que a forma como a família é ou atua não basta e podendo levar à internalização de um sentimento de incompetência (Moreira, 2014).

Assim, mesmo que a terapia seja recomendada como forma de favorecer os fatores de proteção dessa família, ela pode ser compreendida por seus membros como um atestado de incompetência (Relvas, 2013). Não é de surpreender, portanto, que a recomendação da terapia seja vivenciada, em contextos como esse, com ambivalência e sentimentos contraditórios (Relvas, 2013).

Neste caso, percebemos, na narrativa do casal, que a terapia é vista como forma de reconquistar a guarda dos filhos. É possível que houvesse fantasias a respeito de como a visão da terapeuta aumentaria ou diminuiria suas chances de reaverem a guarda dos filhos. Isso fica evidente no fato de o casal jamais ter mencionado à terapeuta que estava fazendo terapia por recomendação, destacando apenas suas motivações pessoais.

Relvas (2013) destaca que, diante de atendimentos a famílias e casais que não buscaram a terapia por iniciativa própria, deve-se ter em mente que pode haver uma confusão sobre quais são os objetivos do processo terapêutico. Será que Fernando e Isabel se sentiram confortáveis para falar sobre aquilo que realmente queriam para sua relação ou falaram apenas sobre aquilo que acreditavam que a instituição gostaria que eles falassem?

Portanto, ao fazer o encaminhamento para um processo psicoterápico, a instituição deve ser clara com a família sobre os seus motivos, mostrando que não se trata de uma nova punição, mas de uma forma de fortalecer os recursos de que a família já dispõe e desenvolver outros que a ajudem a lidar com suas dificuldades. Por sua vez, os terapeutas que recebem esses encaminhamentos devem buscar abrir espaço para discutir, de forma colaborativa, os objetivos de cada um dos membros da família e por que acreditam que foram encaminhados pela instituição. É importante que se possa chegar a um objetivo compartilhado pelos membros da família. A questão do sigilo também deve ser abordada com especial cuidado, para tentar dirimir quaisquer fantasias que possam prejudicar a aliança terapêutica (Relvas, 2013).

\section{VIOLÊNCIA CONJUGAL}

De acordo com a Organização Mundial da Saúde (OMS, 2002), a violência é resultado da complexa interação de fatores individuais, relacionais, sociais, culturais e ambientais. A violência conjugal é uma das formas mais frequentes de violência doméstica, constituindo-se em um problema que afeta especialmente mulheres de todas as idades e de todos os níveis socioeconômicos e culturais (Redondo, Santos, \& Costa, 2004).

De acordo com Dias e Neves (2014), a constituição do vínculo conjugal violento pode ser compreendida a partir de duas linhas teóricas: (a) Estudos feministas: entendem a violência como um ato baseado no gênero, em que o homem age de forma violenta em função do poder e da posição de submissão da mulher no cenário 
conjugal e social; (b) Perspectiva sistêmica: entende que, embora a conjugalidade diga respeito a homens e mulheres que ocupam posições diferenciadas, ambos estão envolvidos no desdobramento da relação violenta. As terapeutas de família feminista reconhecem o valor de ambas as abordagens e propõem sua integração. Elas concordaram que os homens tendem a apresentar maior poder na relação do que as mulheres, mas também defendem que o papel desempenhado por ambos em suas interações deve ser considerado para melhor compreender o fenômeno da violência doméstica, ou seja:

Mantiveram que tanto o feminismo estava correto ao compreender a violência contra a mulher como um ato de imposição do poder e do privilégio masculino, e, ao mesmo tempo, que a Teoria Familiar Sistêmica estava correta ao identificar a participação da mulher no ciclo da violência. (Silverstein, 2003 p. 24)

Adotando-se essa perspectiva para compreender o relacionamento de Isabel e Fernando, identificamos que os dois exibiam diferentes tipos de comportamentos violentos: violência psicológica (quando se diminui ou desqualifica o outro), violência patrimonial (quando se ameaça ou danifica bens que são propriedade do outro) e física (quando se ameaça a integridade física do outro). Podemos sugerir a existência de uma dinâmica de violência mútua, ou seja, em que ambos os cônjuges usam a violência para tentar controlar o outro (Próspero, 2007). Trata-se, porém, de uma definição complexa, pois, mesmo quando a violência se mostra bidirecional, as consequências se mostram mais graves para as mulheres, que apresentam maiores índices de lesões e consequências psicossociais (Anderson, 2004).

Devemos considerar que, mesmo nos casos em que a violência é mútua, o casal continua vivendo em uma sociedade em que o homem tem mais poder do que a mulher e em que esta é cobrada a manter a qualidade das relações familiares. Nesse sentido, mesmo que seja bidirecional, a violência possui impactos qualitativamente diferentes para homens e mulheres (Anderson, 2004). No caso em questão, enquanto Fernando se ausentava por dias de casa, Isabel seguia preocupando-se tanto como o seu desaparecimento como com a subsistência financeira da família.

De acordo com Diniz e Alves (2014), a adesão rígida aos papéis de gênero e a divisão de funções de forma tradicional contribuem para a ocorrência e a manutenção de dinâmicas relacionais violentas. Para Diniz (2011), tanto as relações entre homens e mulheres quanto as relações das mulheres e dos homens entre si são definidas a partir de normas oriundas da construção sócio-históricocultural do "ser homem" e "ser mulher". Percebemos que a preocupação com esses papéis prescritos a homens e mulheres está presente na narrativa de Isabel, que cobra a atuação de Fernando como o provedor da família.

Outra questão a ser abordada se refere ao modo de tratamento utilizado neste estudo: a terapia de casal em casos de violência doméstica. Trata-se de um tema controverso. Existe a preocupação de que o atendimento conjunto possa reforçar a ideia de que ambos os cônjuges são igualmente responsáveis pela violência, o que pode contribuir para o hábito já comum de o perpetrador culpar a vítima (Stith, Rosen, McCollum, \& Thomsen, 2004). Tratar da violência de forma conjunta também pode representar um risco adicional à mulher, já que ela pode ser agredida em função de algo que foi dito em terapia ou pode sequer relatar a violência ao terapeuta, em função da presença do cônjuge (Tutty, Bidgood, \& Rothery, 1993). Por outro lado, alguns autores descrevem resultados positivos com o uso da terapia de casal nesse contexto, por ela permitir trabalhar a dinâmica específica de cada casal, que pode contribuir para a situação de violência (Stith et al., 2004).

Nova Perspectiva Sistêmica, v. 29, n. 67, p. 41-55, agosto 2020. 
De forma geral, a terapia de casal para casos de violência doméstica é fortemente contraindicada se existe controle, subjugação ou intimidação unilateral (Stith et al., 2004). Embora consideremos que esse não seja o caso do casal aqui descrito, já que acreditamos haver um quadro de violência mútua, essa questão deveria ser constante e minuciosamente reavaliada se o casal desse continuidade à terapia.

Os terapeutas de casal nesse contexto também devem se mostrar atentos a como os comportamentos exibidos na sessão podem refletir diferentes fases do ciclo da violência. De maneira geral, a violência conjugal se desenvolve em um ciclo composto por três etapas: (a) conflitos iniciais, que geram tensão entre o casal, (b) episódios de violência decorrentes da falta de controle do agressor diante da tensão entre os cônjuges, (c) demonstrações de arrependimento por parte do agressor, levando à reconciliação do casal. Esse ciclo costuma se repetir, aumentando o nível de violência e diminuindo o intervalo entre as etapas (Paixão et al., 2014). Nesse sentido, podemos retomar dois trechos do relato: (a) as manifestações de afeto entre os cônjuges na sessão: o terapeuta deve se perguntar se essas manifestações sempre se mostraram presentes ou se surgiram de forma repentina. Se for este o caso, é possível que o casal esteja na etapa da reconciliação; (b) se a esposa passa a descrever que quer se expressar melhor para não gerar desentendimentos, devemos nos perguntar se essa mulher está explicitando o seu processo reflexivo ou se está sinalizando temer um novo episódio de violência.

A violência doméstica é um estressor na vida do casal. No entanto, também pode ser exacerbada por outras situações de estresse que o casal esteja vivendo (Anderson, 2004). Portanto, especialmente em famílias multiestressadas, é importante avaliá-la sempre de forma contextualizada, considerando os outros fatores que se mostram presentes na realidade dessa família.

O atendimento terapêutico teve fim com a notícia da separação do casal. Segundo Féres-Carneiro (2003), a opção pela manutenção ou dissolução do laço conjugal está relacionada ao modo como os casais são capazes de efetuar mudanças na interação conjunta, com o objetivo de ampliar seus espaços de crescimento. Dessa forma, manter o relacionamento conjugal nem sempre é o resultado mais desejado. Para alguns casais, o grande desafio é encontrar uma maneira alternativa mais adaptativa para romper o ciclo da violência (Falcke, Wagner, \& Mosmann, 2013). Para Fernando e Isabel, a saída desse ciclo se deu pela separação.

\section{Uso de Álcool e Outras Drogas}

A relação entre a família e o uso de álcool e outras drogas costuma se mostrar bidirecional (Silva, 2015). Por um lado, o uso de substâncias tende a influenciar não apenas aquele que faz uso delas, mas também sua família. Os membros da família tendem a apresentar, nesse contexto, comportamentos de preocupação e vigilância constante, que prejudicam sua qualidade de vida. Por outro lado, o álcool pode ser utilizado como uma estratégia desadaptativa para tentar manejar os conflitos familiares ou o estresse relacionado a eles. Essa relação mútua ajuda a compreender por que a terapia de casal ou familiar tende a apresentar bons resultados no contexto de uso problemático de álcool e outras drogas.

No caso de Fernando e Isabel, podemos identificar como ela busca controlar e reduzir seu uso, caracterizando-se uma dinâmica demandante-evitativa, em que um dos cônjuges busca explicações e mudanças enquanto o outro se distancia (Stanton, 2015). Segundo Stanton (2015), esse padrão pode ser identificado com frequência em casais em que um dos cônjuges apresenta transtornos em relação ao uso do álcool, mostrando-se relacionado aos conflitos resultantes do sofrimento gerado pelo contexto de abuso/dependência.

Nova Perspectiva Sistêmica, v. 29, n. 67, p. 41-55, agosto 2020. 
O abuso/dependência de álcool também tem se mostrado relacionado a maiores dificuldades na interação conjugal, caracterizadas por mais comportamentos negativos (p. ex., queixas, evitação, críticas), assim como menos comportamentos positivos (p. ex., empatia, aprovação, humor) ou de resolução de problemas (p. ex., ser capaz de descrever o problema e de propor soluções; Marshal, 2003).

As dificuldades de comunicação se destacaram no relato do caso. Podemos assinalar aqui as críticas mútuas e a dificuldade de Fernando em se expressar. Para Walsh (2005), em situações estressantes, é importante que a comunicação seja o mais clara possível, uma vez que cada pessoa da família tem uma percepção diferente sobre os acontecimentos. Isso pode ser feito encorajando os membros do grupo familiar a compartilhar o máximo de informações acerca da situação vivenciada de forma a oportunizar mensagens e ações claras, assim como o compartilhamento empático de emoções. É possível perceber pelo tom de voz, pelo conteúdo verbal e pelos padrões de comunicação a qualidade do funcionamento do grupo familiar. "Críticas, acusações e uso de bodes-expiatórios" (Walsh, 2005, p. 107) geram um clima de medo e desconfiança no qual o conflito fica fora de controle. Além disso,

as experiências prévias de violência ou de separação traumática na família nuclear, nos relacionamentos de casal ou nas famílias de origem podem gerar medos catastróficos que podem conduzir a regras familiares não faladas para evitar conflitos, que aumentam os riscos de que as tensões não resolvidas se acumulem e explodam em violência. (Walsh, 2005 p. 107)

Caso o atendimento do casal tivesse prosseguido, teria sido importante compreender a história das famílias de origem de Fernando e Isabel. As experiências na família de origem mostram-se importantes para compreender tanto a violência conjugal (Marasca, Colossi, \& Falcke. 2013) como o uso de álcool e outras drogas (Silva, 2015).

A violência doméstica, o abuso/dependência de álcool e outras drogas e o estresse têm se mostrado correlacionados, de acordo com diferentes estudos (Anderson, 2004; Silva, 2015). Assim, ao se trabalhar com famílias multiestressadas, mostra-se imprescindível que esses diferentes estressores sejam considerados e abordados de forma conjunta e contextualizada.

\section{CONSIDERAÇ̃̃ES FINAIS}

A terapia familiar ou de casal têm como objetivo trabalhar os comportamentos de seus membros e a forma como eles interpretam o que lhes acontece (Minuchin, Nichols, \& Lee, 2009). De acordo com Walsh (2005), a terapia pode, então, ser utilizada como meio para estimular processos que contribuam para o desenvolvimento da família, especialmente no que se refere às suas crenças, aos seus modos de organização e sua comunicação. Esses processos poderiam ser considerados como fatores de proteção para a família e para os seus membros, podendo contribuir, como tal, para minimizar a sua vulnerabilidade. Isso se mostra especialmente relevante no caso das famílias multiestressadas, que têm sua vulnerabilidade aumentada devido aos vários fatores de risco presentes em sua realidade (Brandão, Mahfoud, \& Gianordolli-Nascimento, 2011).

No entanto, deve-se ter em mente que a psicoterapia, de forma isolada, possui uma contribuição bastante limitada nesse sentido. O trabalho com essas famílias deve ser multidisciplinar e apoiado em políticas públicas (Passos e Silva, 2017). 
Os aspectos apontados neste estudo reforçam diversos temas que têm sido abordados na literatura sobre famílias multiestressadas, em especial no que tange ao uso de álcool e outras drogas e à violência doméstica, destacando-se a sobreposição e a interação desses diferentes estressores.

O caso relatado também permitiu levantar hipóteses sobre as repercussões do encaminhamento do casal parental à terapia no contexto de institucionalização dos filhos. Espera-se que esses resultados contribuam para que os profissionais reflitam sobre o desenvolvimento de estratégias que permitam melhorar a realização e o recebimento de encaminhamentos nesse contexto.

A abordagem de famílias multiestressadas tem se constituído em um grande desafio para os terapeutas de família, em especial devido ao fato de que, apesar dos sintomas e crises, muito dificilmente a família admite e/ou reconhece a necessidade de ajuda psicológica (Martínez, 2003). Fernando e Isabel, embora identificando e expressando suas dificuldades, não conseguiram implementar as mudanças desejadas. Utilizando-se o modelo transteórico da mudança, é possível hipotetizar que o casal ainda se encontrasse em um momento contemplativo ou de preparação (Relvas, 2013). Ou seja, antes de efetivamente realizar a mudança, o casal e a família devem ser capazes não apenas de identificar e expressar o problema, mas também estarem motivados para implementar as ações necessárias e terem desenvolvido habilidades para isso. Dessa forma, é importante que os terapeutas e as instituições tenham consciência de que o tempo da família não é o mesmo que o seu e que o processo não é imediato ou veloz como se gostaria.

Estudos futuros podem investigar questões que não foram aprofundadas neste trabalho. No caso de Isabel e Fernando foi possível perceber uma escassez de rede de apoio, já que a mãe de Isabel tinha recém falecido e a de Fernando tinha rompido relações com ele. Estudos futuros poderiam sugerir estratégias que permitissem trabalhar essa questão.

Esperamos que este estudo possa suscitar questionamentos que contribuam para o conhecimento e o atendimento a famílias multiestressadas. Sugerimos que novos relatos de caso sejam publicados para que os profissionais possam compartilhar suas inquietações, hipóteses e estratégias, criando-se uma rede que qualifique, cada vez mais, o atendimento prestado a essas famílias.

\section{REFERÊNCIAS}

Anderson, K. L. (2004). Perpetrator or victim? Relationships between intimate partner violence and well-being. Journal of Marriage and Family, 64, 851-863. https://doi. org/10.1111/j.1741-3737.2002.00851.x

Azôr, A. M. G. C. C., \& Vectore, C. (2008). Abrigar/desabrigar: Conhecendo o papel das famílias nesse processo. Estudos de Psicologia (Campinas), 25(1), 77-89. https://dx.doi.org/10.1590/S0103-166X2008000100008

Calvo, V. G. (2004). Famílias multiproblemáticas, dificuldades de abordaje. Trabajo Social, 6, 145-156. Recuperado de http://search.proquest.com/openview/c540a73 91c2d443c15a0532338b12215/1?pq-origsite $=$ gscholar $\& c b l=2035753$

Cancrini, L., de Gregorio, F., \& Nocerino, S. (1997). Las familias multiproblemáticas. In M. Coletti \& J. L. Linares, J. L. (Eds.), La intervención sistémica en los servicios sociales ante la familia multiproblemática: La experiencia de Ciutat Vella (pp. 45-82). Madrid. Paidós. 
Conselho Nacional de Saúde. (2016). Resolução no 510, de 07 de abril de 2016. Conselho Nacional de Saúde. Recuperado de http://conselho.saude.gov.br/ resolucoes/2016/Reso510.pdf

Conselho Nacional do Ministério Público. (2013). Um olhar mais atento aos serviços de acolhimento de crianças e adolescentes no país. Relatório da resolução 71/2011. Recuperado de http://www.cnmp.mp.br/portal/images/stories/Destaques/ $\underline{\text { Publicacoes }}$

Conselho Nacional dos Direitos da Criança e do Adolescente. (2009). Orientações Técnicas: Serviços de Acolhimento para Crianças e adolescentes. Recuperado de http://www.sdh.gov.br/assuntos/criancas-e-adolescentes/programas

Dias, A. S. F., \& Neves, A. S. (2014). A constituição do vínculo conjugal violento: Estudo de caso. Vinculo - Revista do Núcleo em Saúde Mental e Psicanálise das Configurações Vinculares. 11(1), 8-15. Recuperado de http://pepsic.bvsalud.org/ scielo.php?script=sci arttext\&pid=S1806-24902014000100003

Diniz, G. (2011). Conjugalidade e violência: Reflexões sob uma ótica de gênero. In T. Féres-Carneiro (Ed.), Casal e família - Conjugalidade, parentalidade e psicoterapia (pp. 11-26). São Paulo. SP: Casa do Psicólogo.

Diniz, G. R. S., \& Alves, C. 0. (2014). Gênero, conjugalidades e violência: Uma proposta de intervenção sistêmica-feminista. In C. M. T. Stevens, S. R. D. Oliveira, \& V. Zanello, V. Estudos feministas e de gênero: Articulações e perspectivas (pp. 161-175). Florianópolis, SC: Editora Mulheres.

Falcke, D., Wagner, A., \& Mosmann, C. (2013). Estratégias de resolução de conflito e violência conjugal. In T. Féres-Carneiro (Ed.), Casal e família: Transmissão, conflito e violência (pp.159-176) São Paulo, SP: Casa do Psicólogo.

Féres-Carneiro, T. (2003). Construção e dissolução do laço conjugal na psicoterapia de casal. In T. Féres-Carneiro (Ed.), Família e casal - Arranjos e demandas contemporâneas (pp. 201-274) Rio de Janeiro, RJ: Editora PUC.

Gómez, E., Muñoz, M. M.s \& Haz, A. M. (2007). Famílias multiproblemáticas y en riesgo social: Características e intervención. Psykhe. 16(2), 43-54. http://dx.doi. org/10.4067/S0718-22282007000200004

Lei n.12.010, de 03 de agosto de 2009. (2009). Altera a Lei n. 8.069 de 13 de julho de 1990, o Estatuto da Criança e do Adolescente, e dá outras providências. Brasília, DF: Presidência da República. Recuperado de http://www.planalto.gov.br/ccivil 03/ ato2007-2010/2009/lei/ 112010.htm

Madsen, W. C. (2010). Terapia colaborativa com famílias multiestressadas (2a ed.). São Paulo. SP: Editora Roca.

Marasca, A. R., Colossil, P. M., \& Falcke, D. (2013). Violência conjugal e família de origem: Uma revisão sistemática da literatura de 2006 a 2011. Temas em Psicologia, 21(1), 221-243. http://dx.doi.org/10.9788/TP2013.1-16

Marshal, M. P. (2003). For better or for worse? The effects of alcohol use on marital functioning. Clinical Psychological Review, 23, 959-997. https://doi.org/10.1016/j. cpr.2003.09.002

Martínez, M. R. (2003). La família multiproblemática y el modelo sistémico. Portulária, 3, 89-115. Recuperado de http://rabida.uhu.es/dspace/handle/10272/151.

Moreira, M. I. C. (2014). Os impasses entre acolhimento institucional e o direito à convivência familiar. Psicologia \& Sociedade, 26(n.spe.), 28-37. http://dx.doi. org/10.1590/S0102-71822014000600004

Organização Mundial de Saúde. (2002). Relatório mundial sobre violência e saúde. Recuperado de: http://www.opas.org.br/wp-content/uploads/2015/09/relatorio$\underline{\text { mundial-violencia-saude.pdf }}$ 
Paixão, G. P. do N., Gomes, N. P., Diniz, N. M. F., Couto, T. M., Vianna, L. A. C., \& dos SantoS, S. M. P. (2014). Situações que precipitam conflitos na relação conjugal: O discurso de mulheres. Texto \& Contexto Enfermagem, 23(4), 1041-1049. http:// dx.doi.org/10.1590/0104-07072014003290013

Passos, J. R., \& Silva, I. M. (2017). Perspectivas de profissionais sobre acolhimento de crianças e adolescentes e reintegração familiar. Nova Perspectiva Sistêmica, 59, 71-86. Recuperado de http://pepsic.bvsalud.org/scielo.php?script=sci arttext\&pi $\mathrm{d}=$ S0104-78412017000300006

Pratí, L. E., Couto, M. C. P. D. Pr, \& Koller, S. H. (2009). Famílias em vulnerabilidade social: rastreamento de termos utilizados por terapeutas de família. Psicologia: Teoria e Pesquisa, 25(3), 403-408. http://dx.doi.org/10.1590/S0102-37722009000300014

Polkinghorne, D. E. (1995). Narrative configuration in qualitative analysis. Qualitative Studies in Education, 8(1), 5-21. https://doi.org/10.1080/0951839950080103

Próspero, M. (2007). The effect of coercion on aggression and mental health among reciprocally violent couples. Journal of Family Violence, 23, 195-202. https://doi. org/10.1007/s10896-007-9143-6

Relvas, A. P. (2013). Familias obligadas, terapeutas forzosos. Ciudad de México: Colofón.

Santos, L. V., \& Costa, L. F. (2004). Avaliação da dinâmica conjugal violenta e suas repercussões sobre os filhos. Psicologia: Teoria e Prática, 6(1), 59-72. Recuperado de http://pepsic.bvsalud.org/scielo.php?script=sci_arttext\&pid $=$ S1516-36872004000100005

Serralta, F. B., Nunes, M. L. T., \& Elzirik, C. L. (2011). Considerações metodológicas sobre o estudo de caso na pesquisa em psicoterapia. Estudos de Psicologia (Campinas), 28(4), 501-510. http://dx.doi.org/10.1590/S0103-166X2011000400010

Silva, I. M. (2015). A conjugalidade diante do abuso/ dependência do álcool: uma compreensão sistêmica. In M. F. O. Sudbrack, M. I. G. Conceição, Silva, I. M., \& Lordello, S. R. (Eds), Abramd: Compartilhando saberes (pp. 96-120). Brasília: Technopolitik.

Silverstein, L. B. (2013). Classic texts and early critiques. In L. B. Silverstein \& T. J. Goodrich (Eds.), Feminist family therapy: Empowerment in social contexts (pp. 17-36). Washington: APA.

Sousa, F. G. M. D., Castro, L. B. D., Nogueira, A. L. A., Silva, I. R., Silva, D. C. M. D., \& Amorim, N. M. A. (2014). Significados de família sob o olhar de pais de adolescentes escolares. Revista RENE, 15(3), 480-490. Recuperado de http://repositorio.ufc.br/ bitstream/riufc/11614/1/2014 art fgmsousa.pdf

Sousa, L., \& Ribeiro, C. (2005). Percepção das famílias multiproblemáticas pobres sobre as suas competências. Psicologia, 19(1-2), 169-191. Recuperado de http:// www.scielo.mec.pt/pdf/psi/v19n1-2/v19n1-2a08.pdf

Stanton, M. (2005). Couples and addiction. In M. Norway (Ed.), Handbook of couple's therapy (pp. 313-336). New Jersey: John Wiley \& Sons.

Stith, S. M., Rosen, K. H., McCollum, E. E., \& Thonsen, C. J. (2004). Treating intimate partner violence within intact couple relationships: Outcomes of multi-couple versus individual couple therapy. Journal of Marital and Family Therapy, 30(3), 305-3018. https://doi.org/10.1111/j.1752-0606.2004.tb01242.x

Tutty, L. M., Bidgood, B. A., \& Rothery, M. A. (1993). Support groups for battered women: Research on their efficacy. Journal of Family Violence, 8(4), 325-343. https://doi.org/10.1007/BF00978097

Walsh, F: (2005). Fortalecendo a resiliência familiar. São Paulo. SP. Roca.

Yin, R. K. (2001). Estudo de caso: Planejamento e métodos. Porto Alegre. Bookman Editora. 
Doutoranda em Psicologia na Universidade do Porto - Portugal. Mestre em estressores: um estudo de caso sobre uma terapia de Psicologia - Universidade Católica de Brasília (UCB), com Especialização em Terapia Familiar e de Casais (INTERPSI/PUC-GO) e em Dependências, Abusos e Compulsões - Faculdade de Ciências da Saúde de São Paulo (FACIS).

https://orcid.org/0000-0003-0287-189X

E-mail: anadorispsi@yahoo.com.br

\section{ISABELA MACHADO DA SILVA}

Psicóloga, com especialização em Terapia de Família pelo Domus - Centro de Terapia de Casal e Família. Mestre e Doutora em Psicologia pela Universidade Federal do Rio Grande do Sul (UFRGS), com período de estágio doutoral na University of British Columbia (UBC). Professora do Departamento de Psicologia Clínica do PPG em Psicologia Clínica e Cultura da Universidade de Brasília (UnB). https://orcid.org/0000-0002-9654-9342

E-mail: isabela.ms@gmail.com 